\title{
Understanding the experiences of positive life changes during postgraduate study on a Masters in Applied Positive Psychology programme: An Interpretative Phenomenological Analysis
}

\author{
Christian J. van Nieuwerburgh · Agnieszka Lech
}

\begin{abstract}
There is a global increase in the teaching of positive psychology at postgraduate level. Anecdotally, it has been suggested that university-based positive psychology programmes can be "life changing". This exploratory qualitative study aimed to enhance our understanding of the positive life experiences of students registered on a Masters in Applied Positive Psychology (MAPP) programme. The researcher interviewed five postgraduate students undertaking a MAPP at the University of East London. Interpretative phenomenological analysis was used to identify emerging themes before these were analysed and clustered into a number of overarching themes. Participants reported experiencing a number of positive life changes as a result of the MAPP programme. Key themes that emerged were the sense that there were "myriad different thoughts and potential opportunities"; that studying positive psychology was "like coming home"; that participants enjoyed having time for reflection; and the sense that "it's all about the people". This study raised the question of whether the MAPP programme could, in itself, be considered a positive psychological intervention.
\end{abstract}

Keywords: MAPP, positive life changes, postgraduate, interpretative phenomenological analysis

\section{Introduction}

Positive Psychology has recently shown phenomenal growth (Hefferon \& Boniwell, 2011). This increased interest was initiated by a presidential speech by Professor Martin Seligman at the 1998 American Psychological Association convention. Seligman's key contribution to the field is his commitment to a "scientific grounding" for the discipline. Today, positive psychology is defined as "a science that focuses on the development and facilitation of flourishing environments and individuals" (Hefferon \& Boniwell, 2011, p. 2).

As Positive Psychology continues to build its evidence base and grow in reputation and popularity, it is helpful to gain a better understanding of the experiences of students on postgraduate Applied Positive Psychology programmes in order to comprehend the anecdotally mentioned "life-changing" effect and to inform the development of new programmes. The commitment to a "scientific grounding" led to the foundation of two Masters in Applied Positive Psychology (MAPP) programmes, the first at the University of Pennsylvania in 2005 and the second at the University of East London in 2007 (Hefferon \& Boniwell, 2011). More recently, MAPP programmes have been established at New Bucks University and Anglia Ruskin University in the UK and the University of Melbourne in Australia. It is estimated that there are 
scores of undergraduate positive psychology classes in American, European and British universities (Boniwell, 2008; Fineburg, 2004).

At the same time, there is increasing interest in the impact of further and higher education on the wellbeing of students. However, only a small number of studies has considered the impact on students. US researchers have been interested in the broad impact of post-secondary education on students (e.g. Pascarella \& Terenzini, 2005; Pascarella, Wolniak, Seifert, Cruce \& Blaich, 2005). Although most research focuses primarily on employability and the impact of postsecondary education on career prospects, Pascarella and Terenzini note the broader positive effects of post-secondary education on "cognitive development", "values" and "attitudes" (2005, p. 6). More recently, Cohen (2006) has argued for the re-prioritisation of social and emotional education as distinct from purely academic instruction in schools and universities, suggesting that this will improve the wellbeing of students.

Some research studies support a positive relationship between education and subjective wellbeing (Blanchflower \& Oswald, 2004). However, it is not clear whether the relationship is affected by levels of education or rather by a set of unobservable traits related to interest in learning, such as motivation or intelligence (Dolan, Peasgood, \& White, 2008). It also possible that even if education does not directly influence wellbeing, it might provide people with new skills or better coping mechanisms to deal with daily situations (Ovaska \& Takashima, 2006) which, in turn, could lead to enhanced wellbeing. This context is further complicated by the fact that some studies claim that there are no significant effects of education on one's wellbeing (Dolan et al., 2008; Helliwell, 2002).

Notwithstanding the contradictory findings of researchers, it can be convincingly argued that positive psychology can have an impact beyond the direct teaching of the topic at university level. Schreiner, Hulme, Hetzel and Lopez (2009) point out that "the field of positive psychology offers the opportunity to turn the academic focus to helping students explore what makes life worth living" (p. 569). They identify the challenge of positive psychology as being to raise consciousness and awareness about its principles among a broad university audience (p. 569). While this is an exciting proposition, the teaching of positive psychology at postgraduate level may provide a more immediate and direct impact on students and staff through learning about positive psychology interventions and applying these in their personal and professional lives.

The intention of MAPP programmes is to:

"offer students an opportunity to develop a depth of knowledge and critical understanding of the theory and research within positive psychology, as well as to study and use a range of positive psychology interventions and assessment methods, applying findings of this science to the areas that need it most" (Hefferon \& Boniwell, 2011, p. 214).

The development of the postgraduate teaching of positive psychology has placed the wellbeing agenda at the centre of the curriculum.

Based on their professional experiences of founding and leading postgraduate programmes in positive psychology, Dr Ilona Boniwell and Prof. Martin Seligman have noted a "similarity in the student experience, described by some as a 'life-changing experience'"' (Hefferon \& Boniwell, 2011, p. 214). Boniwell and Seligman suggest that there may be six elements that make the experience positive for students:

- "being 'called' towards this profession"

- "openness to personal transformation"

- "experience of fun or positive emotions"

- "intense intellectual stimulation and rigour" 
- "connectedness with others"

- "being a part of something larger (or larger meaning)"

(as cited in Hefferon \& Boniwell, 2011, p. 215)

In his latest book, Flourish Seligman (2011) identifies three "magical components" in MAPP programmes. He proposes that the content of the programme is "challenging, informative, and uplifting"; in addition, the teaching of positive psychology can be a "personally and professionally transformative" experience; finally, Seligman affirms that positive psychology is a "calling" (p. 64). Here, it is interesting to note the obvious overlap between the three components proposed by Seligman (2011) and the six elements considered by Boniwell and Seligman. This research aims to build on the above studies by undertaking an in-depth exploration of the experiences of students on a MAPP programme.

\section{Methods}

Interpretative Phenomenological Analysis (IPA) is an experiential and phenomenological approach developed by Professor Jonathan Smith at Birkbeck University of London (Smith, 1996; Smith, Flowers \& Larkin, 2009). The approach has been widely embraced within psychology and is now considered to be in the "mainstream" of research methods in the field due to its focus on human experience and agency (Willig \& Rogers, 2008, p. 8). IPA is a suitable research method for this investigation because it seeks to understand the lived experiences of individuals (through tentative, subjectively-derived views) who share experience of a phenomenon (a Masters programme in Applied Positive Psychology). Considering that IPA is inductive in nature-not starting with a hypothesis (Smith et al., 2009) - it is anticipated that it will provide rich data about the experiences of the participants in this study. Importantly, this approach allows both researcher and participants to engage in interpretative activities (Shinebourne, 2011).

\subsection{Design}

An open, semi-structured interview was employed in order to enable participants to consider any aspects of their experience that they considered to be important.

\subsection{Participants}

The participants, four females and one male, were studying for a Masters in Applied Positive Psychology at the University of East London during the 2011-2012 academic year.

\subsection{Procedure}

The study required a small, homogeneous sample of participants registered on a MAPP programme who had experienced positive life changes. Students were invited by email to volunteer for the study. Eight individual responses were received; five participants were able to meet with the researcher during the pre-arranged interview period.

\subsection{Analysis}

At present, there is some flexibility about the use of IPA. Many of the methods applied in this research are those which have been recommended by leading experts in the field: Smith et al. (2009), Smith and Osborn (2008) and Willig (2008). To develop a deep understanding of participants' experiences, transcripts were read and re-read, with the use of initial in-depth, marginal notes, coding and mind maps. 
Initially, 23 "emergent themes" were identified through a process of identifying frequency and prevalence of reference to certain experiences. However, the choice of themes was not limited to prevalence but rather was based on the richness of the description and the relationship of certain accounts of experiences to other themes (Smith et al., 2009). These themes were then presented in a mind map to identify patterns and overlap (see figure 1 below). Following further analysis, additional re-readings of the transcripts and discussion between researchers, the 23 themes were rearranged into ten subthemes. These ten subthemes were then clustered around four overarching themes: "A myriad of different thoughts and potential opportunities"; "It's like I've come home", Time for reflection and "It's about the people".

Figure 1: Mind map of themes and subthemes

\section{Positive life-changing experiences. Themes \& Sub-themes}

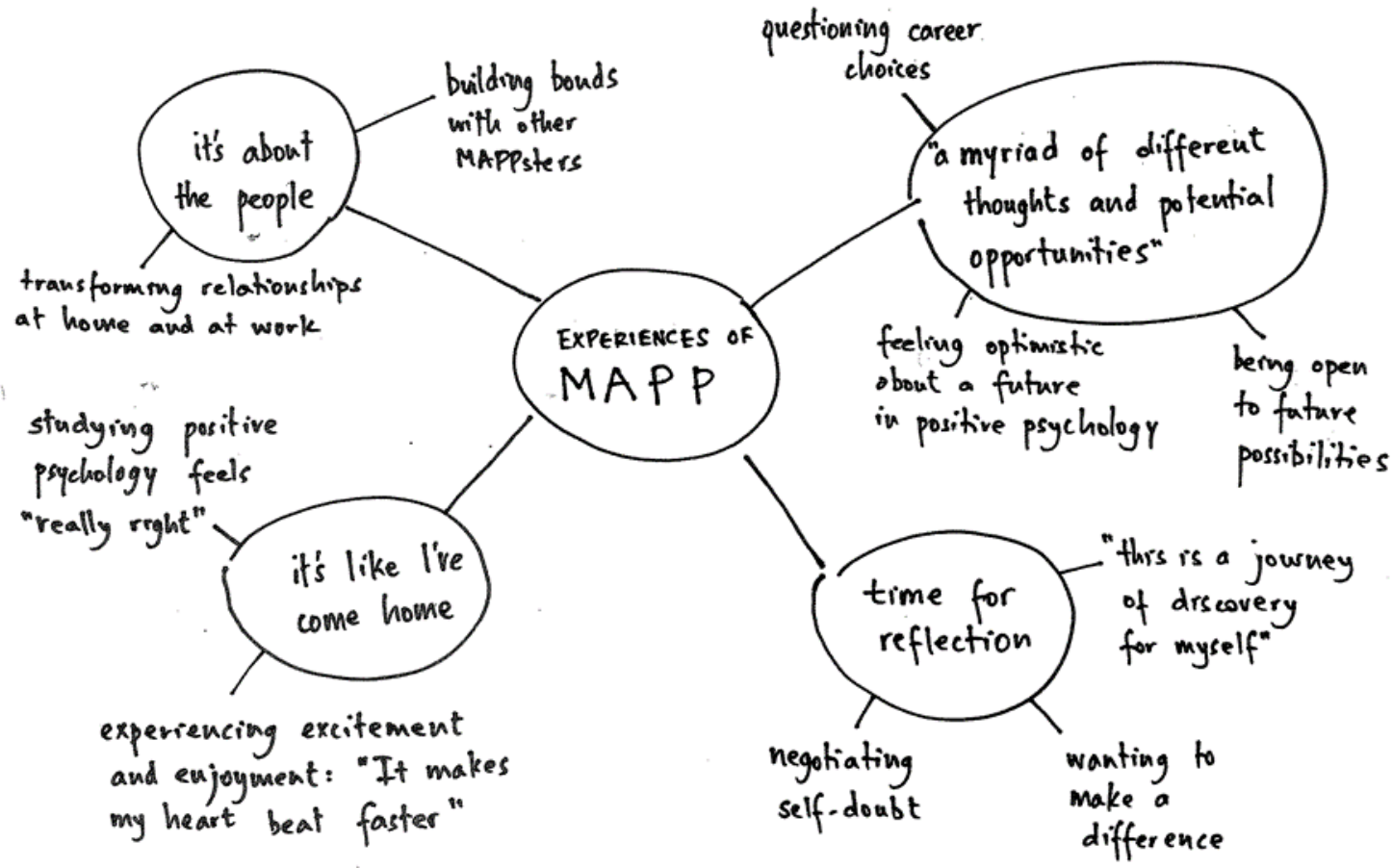

\section{Overview of Findings}

Four key themes relating to the life-changing experiences of postgraduate students completing a Masters in Applied Positive Psychology were identified. Each of the key themes was common to all five participants, although not all subthemes were evident in all interviews.

\subsection{Theme 1: "A myriad of different thoughts and potential opportunities"}

A key theme of the experiences of the five participants of this study relates to a multiplicity of new ideas and potential opportunities that emerged during their period of study. One participant calls it a "myriad of different thoughts and potential opportunities" and this captures the sense of possibility that is generated for all the participants. Either as a result of enrolling on the programme or through their attendance on it, participants start to question past and future career choices and decisions. Hand-in-hand with the questioning of career choices is an openness to a broad range of future opportunities and possibilities. 


\subsubsection{Subtheme 1: Questioning career choices}

All five participants reported the programme invited reflection about their career choices. For some, it led to significant decisions to change career altogether, while it simply raised questions about future directions for others.

The experience of being thoughtful about career choices is apparent across all five participants in this study. This is consistent with the findings of Carr (2011), who refers to longitudinal studies that suggest that people in their forties tend to re-evaluate their family and professional roles ( $\mathrm{p}$. 305). Based on a number of case studies, Seligman (2011) proposes that "learning positive psychology is professionally transforming" (p. 73), suggesting that the changes may be due to the content of the programme. It became apparent that the MAPP programme facilitated the participants' re-evaluation of their professional roles and career choices. This is evidenced by the fact that all the participants reflected on their career choices when talking to the researcher about their experiences and associated the MAPP programme with that reflective process.

\subsubsection{Subtheme 2: Feeling optimistic about a future in positive psychology}

Four of the five participants consistently expressed optimism about their future in the field of positive psychology. Participant 1, for example, reflected on her current level of knowledge and experience:

"Now I have, I've got a body of knowledge, a foundation and I think that I can offer something now....".

She expressed certainty that something "will be revealed" and said that she was "confident" of this happening. Carver, Scheier, Miller \& Fulford (2009) offer a helpful definition of optimism as the expectation of "good things to occur in one's life" (p. 303). They maintain that optimism is associated with a sense of wellbeing. Certainly, all interviewees who expressed optimism about their future in positive psychology were also very upbeat when discussing their futures more generally.

Participant 5 expressed a stronger conviction about a positive future: "I know that this will without doubt be the path to what I do next". She highlighted the strength of her belief:

"the confidence I have in knowing that this is the right path for me is phenomenal -I can't... it is really hard for me to verbalise how strongly I feel that 'that's it - this is my next phase for my life'".

This level of optimism and confidence about their futures is notable but not surprising considering the subject matter of the Masters in Applied Positive Psychology. According to Boniwell (2008), optimists "have a generalised sense of confidence about the future, characterised by their broad expectancy that the outcomes are likely to be positive" (p. 16). It may well be that the participants in this study have "dispositional optimism" or an "Optimistic Explanatory Style" (Hefferon \& Boniwell, 2011), or else they may have learned to be optimistic (Reivich \& Shatte, 2002), which would explain the consistently high levels of confidence about their professional futures. Carver et al. (2009) refer to research and literature that suggests that people with positive expectations deal better with challenges and difficulties than those with negative expectations (p. 309). Based on this assertion and the high levels of confidence expressed during the interviews, it is expected that the participants' likelihood of success will be enhanced. Carr (2011) supports this view when he concludes that optimism can lead to better personal and professional achievement (p. 108). 


\subsubsection{Subtheme 3: Being open to future possibilities}

Taking into account the subject of their postgraduate study, it is perhaps unsurprising that these participants expressed a sense of being open to future possibilities. Participant 5 most eloquently described how she felt about the opportunities that seemed to present themselves:

"So what MAPP has already done is given me a myriad of different thoughts and potential opportunities already..."

\subsection{Theme 2: "It's like I've come home"}

Participants reported a strong sense that the MAPP was the "right" programme for them, with one person saying that it felt like she had "come home". This "fit" between the student and the programme led participants to share experiences and stories which suggested feelings of enjoyment and excitement but also a recognition that this programme provided them with a "home" (comfortable and secure environment) and a place of belonging.

\subsubsection{Subtheme 1: Experiencing enjoyment and excitement: "It makes my heart beat faster"}

Participant 5 captured this sentiment most powerfully when she declared: "it sounds really dramatic but it makes my heart beat faster". The MAPP programme seems to have the effect of creating real excitement for students. The very fact of being with others, studying a topic which is enjoyable and engaging with new ideas makes the programme "amazing". The excitement about the programme and the enjoyment of it seem to be closely linked, as Participant 2 described: "I mean it's amazing to actually be studying something that I really enjoy so much...".

Frederickson's broaden-and-build theory of positive emotions (Frederickson, 1998; 2009) suggests such enjoyment will lead to higher levels of attention and thinking, which allow people to access a broader range of ideas and concepts (Frederickson \& Kurtz, 2011, p. 35). In this way, the enjoyment of participants on the programme enhances their learning experiences and their thinking processes.

In a study aimed at identifying how happiness can be increased and then sustained, Lyubomirsky, Sheldon \& Schkade (2005) propose that a "person's chronic happiness level is governed by 3 major factors: a genetically determined set point for happiness, happiness-relevant circumstantial factors, and happiness-relevant activities and practices" (p. 111). They attribute $50 \%$ of population variation to genetics, $10 \%$ to circumstantial factors (this is low due to the effect of hedonistic adaptation) and $40 \%$ to activities and practices that they term "intentional activity". The choice of participants to undertake postgraduate study in positive psychology accords with the definition of intentional activity as "discrete actions or practices in which people can choose to engage" (p. 118). The authors contend that one crucial element in boosting happiness is "changing one's intentional activities" rather than trying to change one's environment (p. 116). This suggests that the choice of studying for a Masters in Applied Positive Psychology could be a positive psychology intervention (PPI) in its own right, based on Sin and Lyubomirsky's (2009) definition: an intentional activity that "aims to cultivate positive feelings, behaviours, or cognitions" (p. 468).

\subsubsection{Subtheme 2: Studying positive psychology feels "really right"}

Participants not only reported that studying positive psychology is enjoyable, but they also talked about the "fit" of the programme. One of the leading figures in positive psychology, Dr Ilona Boniwell, recounts a similar experience: "When, in 1999, I first heard about positive psychology, I realised immediately that, for me, this was it" (Boniwell, 2008, p. 116). Participant 
2 echoed this sentiment when she acknowledged that the programme "feels really right". Participant 4 described her realisation that the programme would be right for her, reporting that she thought "Oh my God, this is what I've been looking for", while Participant 1 enthused about how it was "just amazing how it's worked out" so that she could study what she'd always been passionate about. In all cases, the strength of feeling about MAPP being "right" is notable.

\subsection{Theme 3: Time for reflection}

For the purposes of this analysis, 'time for reflection' refers to the participants' expression of a need for individual thinking time away from the busy-ness of everyday life.

\subsubsection{Subtheme 1: "This is about a journey of discovery for myself"}

All participants engaged more strongly with this subtheme than any other. One of the most powerful and consistent experiences of the participants was the sense of being on a journey of self-discovery. They noted the relevance of the course content as well as opportunities for personal development and moments of increased self-awareness. The curriculum and course content were referred to as being significant and life changing.

For example, "mindset theory" was mentioned by two of the participants. Participant 1 reported that:

"encounters with certain theories like 'mindset theory' has changed my life". She recognised that "even though I'm a fixed mindset person, I found it stultifying and so boring that I kind of always come out of my cocoon and try to become a butterfly [laughs] out of the chrysalis...".

This realisation is very significant for the participant, allowing her to learn about herself (in her view, being a fixed mindset person) and also seeking to develop a new way of thinking that would allow her to come out of her "cocoon" to see things differently. According to her, this realisation on its own had already changed her life. Learning about "fixed" and "growth" mindsets also had a profound impact on Participant 2. It is interesting to note, however, that Participant 2 had already decided that her year of study on the MAPP programme would be a year of learning and discovery:

"This year, before I left...I moved to London, I thought 'this year is about learning'. It's about learning as much as I possibly can, and trying as much as I possibly can. So, when an opportunity comes up, then I'm going to take it, because that is what this year is about."

It is perhaps because of this that Participant 2 talked the most about the "time to reflect" that had been made available to her. Throughout the interview, Participant 2 highlighted how she felt about having time to "stop and think". She confessed that she appreciated "having the time to reflect", noting that in everyday life "you don't just stop and think". She considered "time" to be a "big gift" to herself. She mused on the outcome of this additional time to "stop and think":

"I don't know if it's serenity, but more...[long pause] maybe acceptance and groundedness with how things are...".

\subsubsection{Subtheme 2: Wanting to make a difference}

Another significant theme to emerge from the interviews with participants is a sense that the MAPP programme helped them to find ways of "making a difference" and making life meaningful. For one participant, a charitable project that developed out of research undertaken for her MAPP dissertation has had a long-term positive impact by providing her with a purpose. She said that the project "gives total meaning to my life. This is what I'm here for". She was 
particularly drawn to this charitable venture because it made her realise that she could "actually really make a difference in these people's lives to help them help themselves". This has shown her and her partner how positive psychology has the "potential to really change things in society". What seemed to motivate this participant more than anything was the realisation that she was able to make a positive intervention into that particular social context and the opportunity to do so.

It could be argued that this desire to "make a difference", expressed by all five participants, may fall under the category of "being part of something larger (or larger meaning)" which has been proposed by Boniwell and Seligman as one of the six factors behind the "magic of MAPP" (as cited in Hefferon \& Boniwell, 2011, p. 215). Batson, Ahmad and Lishner (2009) refer to multiple experiments which suggest that feelings of compassion and empathy can invoke altruistic impulses (p. 424). As a result, it is possible to consider the desire to "make a difference" as a "pro-social motivation" (Batson et al., 2009) or a search for meaning. Our study suggests, however, that for its participants the primary and overriding focus is the desire to "make a difference" in the worlds they inhabit.

\subsubsection{Subtheme 3: Negotiating self-doubt}

Generally speaking, there was an overwhelmingly positive tone to the conversations with participants. Each seemed confident and excited about positive psychology and the potential applications of it within their fields. There was relatively very little mention of self-doubt and when it was discussed it related to feelings when applying for the programme. For example, Participant 3 was pleased to be accepted onto the MAPP programme, as she felt that she didn't have "any kind of social science background and I was a little bit worried about being behind intellectually on that...".

\subsection{Theme 4: "It's about the people"}

Another theme that is consistently mentioned in the context of positive life changes relates to the impact that the MAPP programme has had on personal relationships. All the participants in this study commented positively on the opportunity to meet and learn with other students on the programme (often referred to as "MAPPsters"). In addition, some participants recounted how the MAPP programme had a positive impact on relationships with life partners or work colleagues.

\subsubsection{Subtheme 1: Building bonds with other MAPPsters}

Describing the group of students as a "wonderful brotherhood", Participant 1 explained that "they're very interesting people... really good people. It kind of restores your faith in humanity. They want to do something good for the world". This participant highlighted the collegiality within the group, due to the rigour of the course but also because of a shared desire to "do something good for the world", specifically, a common interest in "making a difference".

Participant 2 had a similar experience, which was expressed in her statement that "the connections that come from [the MAPP programme]...is life changing...". According to this participant, "within a month, three weeks of starting the course I meet eighty-five people in MAPP who are impressive in some way or another even just from their desire to do this and to make a difference". She was very positive about the relationships she had developed with other MAPPsters.

Participant 5 expressed a similar sentiment: "it's the people that you meet here who...which is...I think just the most amazing thing". Based on the experiences of the participants in this study, there 
can be little doubt that MAPPsters have a profound and positive effect on each other. In this case, there is also recognition that the networks extend well beyond the students in the classroom.

\subsubsection{Subtheme 2: Transforming relationships at home and at work}

In addition to the recognition that newly-found relationships with other students will have a positive life-changing effect, some participants reported that their attendance on the MAPP programme had an effect on existing relationships with work colleagues and family members. For example, one participant described how the MAPP programme had a profound impact on a work relationship. As she explained, the relationship between her and the colleague had always been civil but strained. As a result of talking to him about what she was learning on the course, the relationship was completely transformed, as the participant explained:

"He came with a card saying... 'I'm so proud of you'. I know!! And we've never had a fantastic relationship...It made me feel a bit tearful actually...."

"Connectedness with others" also features as one of the six factors highlighted by Boniwell and Seligman (as cited in Hefferon \& Boniwell, 2011, p. 215). Another of the field's founders, Professor Christopher Peterson, was well known for saying the phrase "other people matter" at every positive psychology lecture or workshop that he delivered. In a magazine article, Peterson reiterated that "good relationships with other people may be a necessary condition for our own happiness" (Peterson, 2008).

\section{Conclusion}

\subsection{Wellbeing}

The latest thinking by Seligman (2011) proposes that wellbeing is a construct. Wellbeing, according to Seligman, has five elements: Positive emotion; engagement; relationships; meaning; and accomplishment (PERMA) (Seligman, 2011). The findings of this research study will be explored in light of the above.

Firstly, "positive emotion" relates to both "happiness" and life satisfaction (Frederickson, 1998; Frederickson \& Kurtz, 2011; Diener et al., 2009). Participants reported that they were "happier" as a result of studying for a Masters in Applied Positive Psychology. On the whole, participants used emotive language and emphasised the positive feeling engendered by the programme.

The second element is "engagement", which is related to doing something of interest. According to Seligman (2011), high levels of engagement can lead to the "flow" state (p. 17). Flow is described as a state of complete absorption with an activity and is directly linked to a person's intrinsic motivation (Csikszentmihalyi, 1997). Every participant indicated that they were very engaged on the programme, reporting that it felt "really right", putting the learning into practice and taking every opportunity to learn from the materials, the lecturers and one another.

The third element, positive relationships, is a key feature of the experiences of the participants in this study. Seligman (2011) reconfirms the need for human interaction and collective experiences and correlates these with a sense of wellbeing (pp. 21-23). As discussed above, participants reported that they valued the relationships that they had built with other students on the programme. In addition, some participants reported an improvement on relationships beyond the classroom.

"Meaning" is the fourth element of Seligman's PERMA model. This refers to the experience of "belonging to and serving something that you believe is bigger than the self" (Seligman, 2011, 
p. 17). This is indirectly addressed by the strong desire amongst participants to "make a difference". For some, meaning emerged from their attempts to help others.

The final element is "accomplishment". According to Seligman, this refers to the pleasures of accomplishment or achievement for its own sake. Of all the elements, this is the one least mentioned by participants. However, this may well be due to the fact that all the participants were, through selection, in the process of accomplishing something (i.e. an Masters in Applied Positive Psychology).

It is interesting to note that participants in this study reported positive emotion, engagement with the programme, increased positive relationships and a desire to be involved in more meaningful activities. In other words, studying for a Masters in Applied Positive Psychology may have increased these participants' sense of overall wellbeing.

\subsection{Hope, optimism, self-concordant goals}

From the interviews, it seemed that each of the participants was both hopeful and optimistic. Each interview felt positive and uplifting. Hopefulness and optimism were most evident when participants spoke about their own futures within the field of positive psychology. It has been shown that hopefulness (Snyder et al., 1991) and optimism (Scheier \& Carver, 1993) seem to have a positive effect on subjective wellbeing. Diener, Oishi and Lucas (2009) conclude, "it is not just who we are that matters to happiness, but how we think about our lives" (p. 190). Therefore, the optimism and hopefulness of the participants may also increase their sense of wellbeing.

Furthermore, based on longitudinal studies (e.g. Sheldon \& Elliott, 1998, 1999; Sheldon \& Kasser, 1995, 1998), Lyubomirsky et al. (2005) contend that increases in wellbeing "are most likely when a person chooses and attains self-concordant goals, that is, goals that 'fit' the person" (p. 119). They therefore recommend that people who pursue happiness should look for activities that are "in alignment with their values" (Lyubomirsky et al., 2005, p. 126). Based on the theme "It's like I've come home", participants in this study were pursuing a very self-concordant goal when they applied for a place on the Masters in Applied Positive Psychology programme. Schreiner et al. (2009) also point to a number of researchers who have posited that student learning can be enhanced if students are driven by intrinsic, self-initiated motives (Baxter Magolda, 1999; Connell \& Wellborn, 1991; Ryan \& Deci, 2000).

Taking into account that participants in this study reported increases in four of the five elements of PERMA, and the research that shows that the optimism and hopefulness expressed by participants may have an impact on their wellbeing, it is fruitful to explore whether the MAPP programme is, in itself, a positive psychology intervention.

\subsection{Magic of MAPP}

As noted earlier, Hefferon and Boniwell (2011) have identified "an unexpected similarity in the student experience" between the MAPP programme at the University of Pennsylvania and the MAPP programme at the University of East London (p. 214). Boniwell and Seligman have suggested "six major factors" which constitute what is termed the "Magic of MAPP". These are summarised as "being 'called' towards this profession, openness to personal transformation, experience of fun or positive emotions, intense intellectual stimulation and rigour, connectedness with others and being part of something larger (or larger meaning)" (Hefferon \& Boniwell, 2011, p. 215). The results of this study broadly endorse the six factors, as demonstrated by the detailed analysis of the individual participants' comments. 


\title{
4.4 Limitations
}

Although participants were made aware that the main researcher was a member of staff at the University of East London, this fact may have influenced participants to provide more positive accounts of their experiences. In addition, in order to recruit sufficient participants, students in their first and second years were invited to participate in the study. This resulted in students at different points in their educational experiences being interviewed. It should be acknowledged that students at different points in their study might have different impressions of the programme. However, Smith and Osborn (2008) advise pragmatism when recruiting for such studies, pointing out that willingness to be involved is a key determinant of selection (p. 56). Following the idea of "purposive sampling" (Smith \& Osborn, 2008, p. 56), only students who had experienced positive life-changing experiences were recruited.

\subsection{Implications}

Our initial findings suggest that studying for a Masters in Applied Positive Psychology might have had a positive impact on the wellbeing of the selected participants. This is based on three findings; firstly, that the themes of this study suggest that participants might have experienced at least four of the five elements of PERMA. Secondly, that participants expressed hopefulness and optimism about their futures. As discussed above, this hopefulness and optimism might lead to higher levels of wellbeing. Thirdly, all participants commented positively on their relationship with other MAPP students. It has been suggested that building relationships and connections with others can increase one's own happiness (Diener \& Seligman, 2002; Christakis \& Fowler, 2009). This raises an interesting question that needs further research: Does undertaking a Masters in Applied Positive Psychology increase wellbeing? In other words, is the MAPP a PPI in itself? If so, it has been shown, based on the combined results of 49 studies, that PPIs do enhance wellbeing (Sin \& Lyubomirsky, 2009). Further qualitative and quantitative research in this area is needed. It might be interesting to explore whether similar experiences are reported by postgraduate students studying other, related, topics such as Coaching Psychology.

Based on the tentative findings of our research, it might be useful for potential applicants to the MAPP programme to consider whether to complete the programme full-time (over one year) or part-time (over two years). If the MAPP programme is considered to be a PPI, then research suggests that its duration can moderate the benefits, with interventions over a longer time more likely to produce greater gains in wellbeing (Sin \& Lyubomirsky, 2009, p. 483). Furthermore, current students may find it useful to note that continuing to practise the PPI at the end of the intervention also leads to enhanced wellbeing (Sin \& Lyubomirsky, 2009 ).

\author{
Authors \\ Dr Christian J. van Nieuwerburgh \\ University of East London \\ c.vannieuwerburgh@gmail.com \\ Dr Agnieszka Lech \\ Queen Mary University of London
}

\section{Publishing Timeline}

Received 30 April 2014

Accepted 4 March 2015

Published 30 July 2015 


\section{References}

Batson, C.D., Ahmad, N. \& Lishner, D.A. (2009). Empathy and altruism. In S.J. Lopez \& C.R. Snyder (Eds.), Oxford handbook of positive psychology (2nd ed.) (pp. 417-426). Oxford: OUP. http://dx.doi.org/10.1093/oxfordhb/9780195187243.013.0039

Baxter Magolda, M.B. (1999). Creating contexts for learning and self-authorship: Constructive-developmental pedagogy. Nashville, TN: Vanderbilt University Press.

Blanchflower, D. G., \& Oswald, A. J. (2004). Well-being over time in Britain and the USA. Journal of Public Economics, 88, 1359-1386. http://dx.doi.org/10.1016/S0047-2727(02)00168-8

Boniwell, I. (2008). Positive psychology in a nutshell. (2nd ed.). London: PWBC.

Carr, A. (2011). Positive psychology: The science of happiness and human strengths. (2nd ed). Hove: Routledge.

Carver, C.S., Scheier, M.F., Miller, C.J., \& Fulford, D. (2009). Optimism. In S.J. Lopez \& C.R. Snyder (Eds.), Oxford handbook of positive psychology (2nd ed.). (pp. 303-311). Oxford: OUP. http://dx.doi.org/10.1093/oxfordhb/9780195187243.013.0028

Christakis, N., \& Fowler, J. (2009). Connected: The surprising power of our social networks and how they shape our lives. New York: Little, Brown \& Company.

Cohen, J. (2006). Social, emotional, ethical, and academic education: Creating a climate for learning, participation in democracy, and well-being. Harvard Educational Review 76(2), 201-237. http://dx.doi.org/10.17763/haer.76.2.j44854x1524644vn

Connell, J.P., \& Wellborn, J.G. (1991). Competence, autonomy and relatedness: A motivational analysis of self-system processes. In M.R. Gunnar \& L.A. Stroufe (Eds.). Minnesota symposium on child psychology: Vol. 22, (pp. 43-77). Hillsdale, NJ: Erlbaum.

Csiksentmilahyi, M. (1997). Finding flow: The psychology of engagement with everyday life. New York: Basic Books.

Diener, E., Oishi, S., \& Lucas, R.E. (2009). Subjective well-being: The science of happiness and life satisfaction. In S.J. Lopez \& C.R. Snyder (Eds.), Oxford handbook of positive psychology (2nd ed.) (pp. 187194). Oxford: OUP. http://dx.doi.org/10.1093/oxfordhb/9780195187243.013.0017

Diener, E., \& Seligman, M. E. P. (2002). Very happy people. Psychological Science, 13, 81-84. http://dx.doi.org/10.1111/1467-9280.00415

Dolan, P., Peasgood, T., \& White, M. (2008). Do we really know what makes us happy? A review of the economic literature on the factors associated with subjective well-being. Journal of Economic Psychology, 29(1), 94-122. http://dx.doi.org/10.1016/j.joep.2007.09.001

Fineburg, A. C. (2004). Introducing positive psychology to the introductory psychology student. In P.A. Linley, \& S. Joseph (Eds.), Positive psychology in practice (pp. 197-209). Hoboken, NJ: Wiley. http://dx.doi.org/10.1002/9780470939338.ch12

Frederickson, B.L. (1998). What good are positive emotions? Review of General Psychology, 2, 300-319. http://dx.doi.org/10.1037/1089-2680.2.3.300

Frederickson, B.L. (2009). Positivity: Groundbreaking research reveals how to embrace the hidden strength of positive emotions, overcome negativity, and thrive. New York: Crown.

Frederickson, B.L., \& Kurtz, L.E. (2011). Cultivating positive emotions to enhance human flourishing. In S.I. Donaldson, M. Csikszentmihalyi, \& J. Nakamura (Eds.), Applied positive psychology: Improving everyday life, health, schools, work, and society (pp. 35-47). London: Routledge.

Hefferon, K., \& Boniwell, I. (2011). Positive psychology: Theory, research and applications. London: Open University Press.

Helliwell, J. F. (2002). How's life? Combining individual and national variables to explain subjective well-being. National Bureau of Economic Research, Working Paper W9065.

Lyubomirsky, S., Sheldon, K.M., \& Schkade, D. (2005). Pursuing happiness: The architecture of sustainable change. Review of General Psychology 9(2), 111-131. http://dx.doi.org/10.1037/10892680.9.2.111

Ovaska, T., \& Takashima, R. (2006). Economic policy and the level of self-perceived well-being: An international comparison. The Journal of Socio-Economics, 35(2), 308-325. http://dx.doi.org/10.1016/j.socec.2005.11.054 
Pascarella, E. T., \& Terenzini, P. T. (2005). How college affects students: A third decade of research: Vol. 2. San Francisco, CA: Jossey-Bass.

Pascarella, E., Wolniak, G., Seifert, T., Cruce, T., \& Blaich, C. (2005). Liberal arts colleges and liberal arts education: New evidence on impacts. San Francisco, CA: Jossey-Bass.

Peterson, C. (2008). Other people matter: Two examples. Psychology Today, (2008, June 17). http://www.psychologytoday.com/blog/the-good-life/200806/other-people-matter-two-examples

Reivich, K., \& Shatte, A. (2002). The resilience factor: Seven keys to finding your inner strength and overcoming life's hurdles. New York: Broadway.

Ryan, R.M., \& Deci, E.L. (2000). Self-determination theory and the facilitation of intrinsic motivation, social development, and well-being. American Psychologist, 55(1), 68-78. http://dx.doi.org/10.1037/0003-066X.55.1.68

Scheier, M.F., \& Carver, C.S. (1993). On the power of positive thinking: The benefits of being optimistic. Current Directions in Psychological Science, 2, 26-30. http://dx.doi.org/10.1111/1467-8721.ep10770572

Schreiner, L.A., Hulme, E., Hetzel, R. \& Lopez, S. (2009). Positive psychology on campus. In S.J. Lopez \& C.R. Snyder (Eds.), Oxford handbook of positive psychology (2nd ed.). (pp. 569-578). Oxford: OUP. http://dx.doi.org/10.1093/oxfordhb/9780195187243.013.0054

Seligman, M.E.P. (2011). Flourish: A new understanding of happiness and well-being-and how to achieve them. London: Nicholas Brealey.

Sheldon, K.M., \& Elliot, A.J. (1998). Not all personal goals are personal: Comparing autonomous and controlled reasons for goals as predictors of effort and attainment. Personality and Social Psychology Bulletin, 24, 546-557. http://dx.doi.org/10.1177/0146167298245010

Sheldon, K.M. \& Elliot, A.J. (1999). Goal striving, need-satisfaction, and longitudinal well-being: The selfconcordance model. Journal of Personality and Social Psychology, 76, 482-497. http://dx.doi.org/10.1037/0022-3514.76.3.482

Sheldon, K.M., \& Kasser, T. (1995). Coherence and congruence: Two aspects of personality integration. Journal of Personality and Social Psychology, 68, 531-543.http://dx.doi.org/10.1037/0022-3514.68.3.531

Sheldon, K.M. \& Kasser, T. (1998). Pursuing personal goals: Skills enable progress but not all progress is beneficial. Personality and Social Psychology Bulletin, 24, 1319-1331. http:/dx.doi.org/10.1177/01461672982412006

Shinebourne, P. (2011). Interpretative phenomenological analysis. In N. Frost (Ed.). Qualitative research methods in psychology: combining core approaches. Maidenhead: Open University Press.

Sin, N.L., \& Lyubomirsky, S. (2009). Enhancing well-being and alleviating depressive symptoms with positive psychology interventions: A practice-friendly meta-analyis. Journal of Clinical Psychology 65(5), 467-487. http://dx.doi.org/10.1002/jclp.20593

Smith, J.A. (1996). Beyond the divide between cognition and discourse: Using interpretative phenomenological analysis in health psychology. Psychology E Health, 11, 261-71. http://dx.doi.org/10.1080/08870449608400256

Smith, J.A., Flowers, P., \& Larkin, M. (2009). Interpretative phenomenological analysis: Theory, method and research. London: Sage.

Smith, J. A., \& Osborn, M. (2008). Interpretative phenomenological analysis. In J.A. Smith (Ed.). Qualitative psychology: A practical guide to research methods. (2nd ed.). (pp. 53-80). London: Sage.

Snyder, C.R., Harris, C., Anderson, J.R., Holleran, S.A., Irving, L.M., Sigmon, S.T., ... Harney, P. (1991). The will and the ways: Development and validation of an individual differences measure of hope. Journal of Personality and Social Psychology, 60, 570-585. http://dx.doi.org/10.1037/0022-3514.60.4.570

Willig, C. (2008). Introducing qualitative research in psychology: Adventures in theory and method. Maidenhead: Open University Press.

Willig, C., \& Rogers, W. (Eds.). (2008). The Sage handbook of qualitative research in psychology. London: Sage. 